\title{
DIRETIVAS ANTECIPADAS: UMA ANÁLISE DOCUMENTAL NO CONTEXTO MUNDIAL
}

\author{
Silvana Bastos $\operatorname{Cog}^{1}$, Valéria Lerch Lunardi²
}

\begin{abstract}
${ }^{1}$ Doutoranda em Enfermagem do Programa de Pós-Graduação em Enfermagem da Universidade Federal de Rio Grande (FURG). Professora da Universidade Federal de Santa Maria (UFSM) do curso de Enfermagem Campus Palmeira das Missões.

${ }^{2}$ Doutora em Enfermagem. Professora do Programa de Pós-Graduação em Enfermagem da FURG. Rio Grande, Rio Grande do Sul. Brasil. E-mail: vlunardi@terra.com.br
\end{abstract}

\section{RESUMO}

Objetivo: conhecer as legislações referentes ao testamento vital em diferentes países, estabelecendo um paralelo com a instituída no Brasil. Método: realizou-se análise documental de legislações governamentais nacionais e estrangeiras, adotando a análise de conteúdo de Bardin nos materiais localizados até 2013.

Resultados: aproximadamente quinze países possuem legislações regulamentadoras do testamento vital, enquanto que, no Brasil, há apenas uma resolução do Conselho Federal de Medicina. As diretivas antecipadas da vontade ou o testamento vital, nomenclatura adotada no Brasil, atua na preservação da autonomia do paciente.

Conclusão: conhecer as legislações em diferentes países contribui no sentido de subsidiar discussões e avanços legais, no Brasil, para que os profissionais da saúde, que atuam com pacientes, possam considerar os desejos dos assistidos.

DESCRITORES: Diretivas antecipadas. Testamentos quanto à vida. Legislação como assunto. Doente terminal.

\section{ADVANCE DIRECTIVES: A DOCUMENTARY ANALYSIS IN GLOBAL CONTEXT}

\begin{abstract}
Objective: to know the laws regarding living wills in different countries, establishing a parallel with established in Brazil.

Method: there was documentary analysis of domestic and foreign governmental laws, adopting the content analysis of Bardin in the material identified until 2013.

Results: approximately fifteen countries have regulatory laws of the living will, whereas in Brazil there is only one resolution of the Federal Council of Medicine. Advance directives will or living will, nomenclature adopted in Brazil, operates in the preservation of patient autonomy. Conclusion: know the laws in different countries contributes, to support discussions and legal developments in Brazil, so that health professionals who work with patients, may consider the wishes of the beneficiaries.
\end{abstract}

DESCRIPTORS: Advance directives. Living will. Legislation as topic. Terminally ill.

\section{DIRECTIVAS ANTICIPADAS: UN ANÁLISIS DOCUMENTAL EN CONTEXTO GLOBAL}

\section{RESUMEN}

Objetivo: conocer las leyes relativas a los testamentos vitales en diferentes países, estableciendo un paralelismo con lo establecido en Brasil. Metodo: se realizá análisis documental de las leyes gubernamentales nacionales y extranjeras, adoptando el análisis de contenido de Bardin en los materiales localizados até 2013.

Resultados: aproximadamente quince países tienen leyes reguladoras del testamento en vida, mientras que en Brasil sólo hay una resolución del Consejo Federal de Medicina. Las directivas anticipadas serán o testamento vital, nomenclatura adoptada en Brasil, opera en la preservación de la autonomía del paciente.

Conclusión: conozca las leyes de los distintos países contribuye, para apoyar los debates y desarrollos legales en Brasil, por lo que los profesionales de la salud que trabajan con los pacientes, pueden considerar los deseos de los beneficiarios.

DESCRIPTORES: Directivas antecipadas. Volunta em vida. Legislación como assunto. Enfermo terminal. 


\section{INTRODUÇÃO}

O desenvolvimento das ciências tecnológicas biomédicas tem provocado mudanças significativas na atenção prestada ao paciente, considerando os recursos disponíveis para o tratamento de doenças antes consideradas incuráveis. No entanto, em determinados momentos, o aparato tecnológico não é suficiente para manter a vida, em se tratando dos doentes terminais. A tentativa de curar pode acarretar o prolongamento artificial da vida, a perda da autonomia pessoal e da dignidade humana, suscitando discussões acerca de supostos direitos do paciente em manifestar a sua vontade em situações de incapacidade.

Nessa direção, diante da possibilidade da construção de um instrumento para a manifestação dos interesses ${ }^{1}$ é que surgem as Diretivas Antecipadas de Vontade (DAV), habitualmente conhecidas no Brasil como Testamento Vital (TV), que se vinculam à possibilidade de o paciente manifestar previamente sua vontade acerca dos tratamentos médicos (diálise, respiradores artificiais, ressuscitação cardiorrespiratória - RCR, tubo de alimentação) aos quais quer ou não submeter-se caso futuramente esteja em estado de incapacidade. ${ }^{2}$

As DAV emergiram nas últimas décadas como uma das principais discussões da bioética mundial e como garantidoras da preservação da autonomia pessoal. Países como Alemanha, Argentina, Áustria, Bélgica, Estados Unidos da América (EUA), França, Holanda, Hungria, Inglaterra, México, Porto Rico, Portugal, União Européia e Uruguai já possuem legislação específica sobre o tema. No Brasil inexiste uma legislação jurisprudencial sobre o tema, contudo foi editada, pelo Conselho Federal de Medicina (CFM), a Resolução 1.995/12 que trata e autoriza a prática das DAV. ${ }^{3}$

Partindo desse pressuposto, a DAV está ancorada na ideia de que é um processo que inclui a noção de paciente ativo que participa na tomada de decisões relativas à sua saúde. ${ }^{4}$ Em pesquisa realizada no Brasil, com o propósito de identificar a percepção de pacientes oncológicos e de seus acompanhantes em relação ao TV, foi identificado que ambos os grupos desconhecem o significado desse termo. A partir da apresentação de seu significado, constatou-se que pacientes que se encontram em tratamento há mais tempo apresentam maior desejo de decidir sobre seu processo de morrer, e pacientes mais jovens são menos propensos à sua preparação. No entanto, as decisões dos familiares, médicos, pacientes e de pacientes juntamente com seus médicos são bem aceitas por ambos os grupos pesquisados. Desse modo, a partir dessa pesquisa, a implantação do TV, no Brasil, parece ser bem acolhida, tanto por pacientes oncológicos como pelos seus acompanhantes. ${ }^{5}$

Assim, partindo desse estudo e da crença de que muitos são os entraves e dilemas relacionados ao exercício da autonomia pelo paciente, existe a necessidade de fomentar a discussão acerca do TV no Brasil, de modo a contribuir para que os pacientes tenham respeitadas as suas vontades e para que os profissionais que trabalham com pacientes terminais tenham respaldadas as suas atuações, já que as ações em situações de terminalidade são, por diversos momentos, permeadas por conflitos éticos. As DAV são uma via de determinar não apenas o tipo, mas também a intensidade do tratamento médico que a pessoa pensa querer. ${ }^{6}$

Considerando a relevância do tema e a possibilidade de o paciente previamente decidir e registrar como deseja ser cuidado no fim da vida, auxiliando os profissionais de saúde, bem como os familiares a tomarem decisões, além da necessidade de empenhar esforços para que se tenham orientações melhor definidas sobre o TV, delineou-se como questão de pesquisa: Quais as orientações apresentadas nas legislações de diferentes países sobre o TV e a DAV? Assim, objetiva-se neste estudo conhecer as legislações referentes às DAV e ao TV em diferentes países, estabelecendo um paralelo com a vigente no Brasil.

\section{MÉTODO}

Trata-se de uma pesquisa que adota procedimentos da análise documental, como um delineamento que permite explanar e esclarecer a questão / problema em concordância com o objetivo do pesquisador. Um documento é um importante meio de acesso para a compreensão do contexto social, dos conceitos e para o favorecimento de uma observação de um passado recente, além de favorecer a observação do processo de maturação ou de evolução dos indivíduos, grupos, conceitos, conhecimentos, comportamentos, mentalidades e práticas. ${ }^{7}$

$\mathrm{Na}$ análise documental, primeiramente, é necessário localizar os documentos pertinentes e avaliar sua credibilidade; desse modo, essa etapa consistiu na localização das legislações referentes ao TV de diferentes países. ${ }^{7}$ Recorreu-se ao site especializado em divulgar o TV no Brasil que disponibiliza as legislações. Após a primeira seleção realizada no período de setembro a outubro de 2013 e de posse das legislações, optou-se pela confirmação dos documentos nos endereços referenciados no 
site dos seguintes países: EUA, Espanha, Portugal, Argentina, Uruguai, Bélgica, Holanda, Inglaterra, México, União Européia e Brasil. ${ }^{8}$

Os documentos estrangeiros foram selecionados de acordo com os seguintes critérios: pertinência do conteúdo ao objetivo do estudo; confiabilidade, por se tratarem de documentos oficiais elaborados pelos governos; e documentos nos idiomas: inglês, espanhol e português. Os arquivos públicos onde constam os documentos governamentais, os do estado civil, bem como documentos de natureza notarial ou jurídica, constituem documentos públicos passíveis de serem pesquisados mediante análise documental. ${ }^{7}$ Desse modo, foram desconsiderados, em virtude do idioma, as legislações da Áustria, França, Alemanha e Hungria, bem como as legislações da Holanda, Porto Rico e União Européia que não foram localizadas. No Brasil, em virtude da ausência de legislação sobre TV, recorreu-se, a fim de subsidiar justificativas à sustentação da prática das DAV, à Constituição Federal, ${ }^{9}$ ao Código Civil, ${ }^{10}$ ao Código de Ética Médica (CEM) ${ }^{11}$ e à Resolução 1.995/12. ${ }^{3}$

Assim, a partir desses documentos, foi realizada a análise documental preliminar de acordo com as cinco dimensões: análise do contexto, autores, autenticidade e confiabilidade do texto, natureza do texto, conceitos-chave e lógica interna do texto. ${ }^{7}$ Com relação ao contexto do TV, ocorreu, incipientemente nos EUA, em 1967, pela Sociedade Americana para a Eutanásia, como um documento de cuidados antecipados em que o indivíduo poderia deixar registrados seus interesses referentes a interrupções de tratamentos médicos que mantivessem sua vida em situações de terminalidade, além de contribuir com a possibilidade de amenizar conflitos entre profissionais, pacientes terminais e familiares relacionados às decisões dos tratamentos a que o paciente em estado de terminalidade deveria ser submetido. ${ }^{12}$

Partindo do exposto, casos como de Karen Ann Quinlan, Terri Schiavo e Nancy Cruzan, que permaneceram em estado vegetativo persistente, cujos representantes solicitaram a retirada dos suportes que prolongavam suas vidas, impuseram valor decisivo para a criação de lei acerca do tema nos EUA, em 1990, despertando a necessidade de legislação em outros países. ${ }^{1}$ No Brasil, após longos anos de discussão, em 2012, foi aprovada a Resolução sobre as DAV pelo CFM. ${ }^{3}$

No que se refere à autenticidade e à confiabilidade do material analisado, os documentos constituem-se em legislações, ou seja, são documentos jurídicos autênticos e confiáveis, analisados na íntegra, apresentando instruções referentes à implementação das DAV e do TV nos países. Os documentos analisados ilustram exclusivamente $\mathrm{o}$ direito dos pacientes de exercerem sua autonomia diante de uma situação de terminalidade, a partir das exposições referentes aos procedimentos adotados para organizar um TV. As legislações e a única resolução analisada retratam de maneiras bastante similares as ações diante do TV, não se perdendo no sentido amplo de garantir a dignidade e autonomia pessoal para o paciente incapaz.

Em seguida, na última etapa, procedeu-se à análise dos documentos quanto à sua lógica interna, recorrendo-se à análise de conteúdo ${ }^{13}$ pertinente à analise documental. ${ }^{7} \mathrm{~A}$ análise de conteúdo é um conjunto de técnicas de análise das comunicações verbal e não verbal que visa, por meio de procedimentos sistemáticos e objetivos de descrição do conteúdo das mensagens, a obter indicadores, qualitativos ou não, que permitam a inferência de conhecimentos relativos às condições de produção/ recepção dessas mensagens. ${ }^{13}$

Assim, procedeu-se a pré-análise, a exploração do material e o tratamento dos resultados. ${ }^{13}$ A pré-análise constituiu a fase de organização dos dados e compreendeu: a leitura na íntegra, respeitando as normas de validade que se referem à: exaustividade, representatividade, homogeneidade e pertinência. A fim de organizar o material à análise e à realização da leitura flutuante, foram extraídos dos textos informações referentes ao país, ano, o que estabelece a legislação, direitos dos pacientes e a dinâmica de aplicabilidade das DAV.

$\mathrm{Na}$ exploração do material, que consistiu na operação de codificação, utilizou-se, do recorte do texto, o tema, como unidade de registro, que originou as categorias reunindo um grupo de elementos, sob um título genérico, em razão dos caracteres comuns. ${ }^{13} \mathrm{E}$, por fim, a última etapa da análise de conteúdo se propôs à inferência nas interpretações previstas em torno de dimensões teóricas sugeridas pela leitura do material; para isso, foi utilizado referencial da bioética e a legislação brasileira, o que possibilitou refletir sobre as legislações.

Complementa-se, ainda, que esta pesquisa se isenta do Termo de Consentimento Livre e Esclarecido (TCLE) por seu caráter documental. Como os documentos analisados nesta pesquisa foram extraídos de sites governamentais e departamentais de domínio público, os aspectos éticos foram respeitados, considerando que as informações expostas traduzem o que tratam as legislações encontradas. Ressalta-se que essa pesquisa isenta-se de financiamentos externos, sendo de responsabilidade das autoras. 


\section{RESULTADOS E DISCUSSÃO}

$\mathrm{Na}$ atualidade, as discussões referentes ao TV e às DAV tornam-se relevantes em virtude de possibilitar aos pacientes o exercício da autonomia, e aos profissionais da saúde e familiares informações sobre os desejos em situações difíceis, isentando-os da responsabilidade em decidir sobre condutas que, talvez, fossem repudiadas pelos pacientes. Assim, o quadro 1 ilustra os países, as legislações, o ano de sua criação e o que tratam as leis que foram consideradas nessa pesquisa, a fim de propiciar uma discussão paralelamente ao instituído no Brasil.

\section{Quadro 1 - Legislações sobre diretivas antecipadas e testamento vital em diferentes países}

\begin{tabular}{|c|c|c|c|}
\hline País & Ano & Legislação & Sobre o que estabelece \\
\hline EUA $^{14}$ & 1991 & $\begin{array}{l}\text { Patient Self Determination } \\
\text { Act of } 1990\end{array}$ & $\begin{array}{l}\text { Direito do paciente à autodeterminação e a fazer uma diretiva } \\
\text { antecipada, em suas duas modalidades: testamento vital e mandato } \\
\text { duradouro }\end{array}$ \\
\hline Espanha $^{15}$ & 2002 & $\begin{array}{l}\text { Lei n. } 41 \text { de } 14 \text { de } \\
\text { novembro de } 2002\end{array}$ & $\begin{array}{l}\text { Direitos e obrigações de pacientes, usuários e profissionais, bem } \\
\text { como de escolas e serviços de saúde, públicos e privados, sobre a } \\
\text { autonomia do paciente, informações clínicas e documentação }\end{array}$ \\
\hline Bélgica $^{16}$ & 2002 & Lei de 22 de agosto de 2002 & Lei sobre os direitos dos pacientes belgas \\
\hline Inglaterra $^{17}$ & 2005 & $\begin{array}{l}\text { Lei da capacidade mental } \\
\text { de } 2005\end{array}$ & Lei da capacidade mental \\
\hline México $^{18}$ & 2008 & $\begin{array}{l}\text { Lei n. } 247 \text { de } 7 \text { de janeiro } \\
\text { de } 2008\end{array}$ & Lei da vontade antecipada para o distrito Federal \\
\hline Uruguai $^{19}$ & 2009 & $\begin{array}{l}\text { Lei n. } 18.473 \text { de } 03 \text { de abril } \\
\text { de } 2009\end{array}$ & Vontade antecipada \\
\hline Argentina $^{20}$ & $\begin{array}{l}2009 \\
2012\end{array}$ & $\begin{array}{l}\text { Lei n. } 26.529 \text { de } 21 \text { de } \\
\text { outubro de } 2009 \text { revogada } \\
\text { pela lei n. } 26742 \text { de } 24 \text { de } \\
\text { maio de } 2012\end{array}$ & $\begin{array}{l}\text { Estabelece os direitos do paciente e sua relação com os profissionais } \\
\text { e instituições de saúde }\end{array}$ \\
\hline Portugal $^{21}$ & 2012 & $\begin{array}{l}\text { Lei n. } 25 \text { de } 16 \text { de junho de } \\
2012\end{array}$ & $\begin{array}{l}\text { Regula as DAV, designadamente sob a forma de TV, e a nomeação } \\
\text { de procurador de cuidados de saúde, criando o Registro Nacional } \\
\text { do Testamento Vital }\end{array}$ \\
\hline Brasil $^{3}$ & 2012 & $\begin{array}{l}\text { Resolução n. } 1995 \text { de } 31 \text { de } \\
\text { agosto de } 2012 \text { do CFM }\end{array}$ & Dispõe sobre as DAV dos pacientes \\
\hline
\end{tabular}

Há de se destacar que existe uma proliferação vocabular dos termos referentes às DAV e ao TV, distinta nos diferentes países pesquisados. A declaração antecipada de vontade é designada nos EUA por "living testament" ou "advance directive"; na Bélgica, ${ }^{16}$ por "testament biologique"; na Espanha, ${ }^{15}$ "Instrucciones previas"; no Uruguai ${ }^{19}$ e no México, "Voluntad anticipada"; em Portugal ${ }^{21}$ e no Brasil, ${ }^{3}$ "Diretivas antecipadas de vontade" e, na Argentina, ${ }^{20}$ "Directivas anticipadas".

Ao realizar a leitura e a análise dos conteúdos das legislações dos diferentes países, foi possível perceber similaridades de orientações das condutas na aplicação das diretivas antecipadas, emergindo e constituindo-se duas categorias: diretivas antecipadas e o direito ao respeito da autonomia do paciente.

\section{Diretivas antecipadas}

As DAV, encontradas no cenário mundial há anos, foram introduzidas no cenário nacional em
2012. A Resolução 1.995/2012 norteia a conduta médica em situações de terminalidade, garantindo a autonomia do paciente e a manutenção da dignidade humana. ${ }^{3}$ De acordo com a resolução, as DAV constituem-se em um conjunto de desejos, prévia e expressamente manifestados pelo paciente, que serão considerados, sobre cuidados e tratamentos que quer, ou não, receber no momento em que estiver incapacitado de expressar, livre e autonomamente, sua vontade. Além disso, a resolução no Brasil cogita a possibilidade de o paciente designar um procurador para que as suas vontades sejam respeitadas quando esse não puder mais manifestá-la. ${ }^{3}$

Nos EUA, primeiro país a apresentar uma legislação sobre a temática, a diretiva antecipada é uma instrução escrita, como um testamento em vida ou mandato duradouro do advogado para a saúde, reconhecida pela legislação do Estado e relativa à prestação de tais cuidados quando o indivíduo está incapacitado, e deve ser documentada no prontuário do indivíduo; além disso, os funcionários e a 
comunidade devem ser esclarecidos sobre questões relacionadas com as diretivas antecipadas. ${ }^{14}$

A Espanha, primeiro país europeu a legislar sobre as diretivas antecipadas, trata, em linhas gerais, que devem conter orientações à equipe médica sobre o desejo de que não se prolongue artificialmente a vida, a não utilização dos tratamentos extraordinários, a suspensão do esforço terapêutico e a utilização de medicamentos para diminuir a dor, entre outras. ${ }^{15}$ Complementa-se, ainda, que as diretivas antecipadas podem ser revogadas a qualquer momento independentemente de o paciente deixar um registro escrito. Com efeito, a fim de garantir a eficácia das instruções manifestadas pelos pacientes, na Espanha, foi criado no Ministério da Saúde um Registro Nacional de instruções, a fim de que os pacientes sejam atendidos, de acordo com regras estabelecidas por acordo regulamentado pelo Conselho Interterritorial de Saúde. ${ }^{15}$

$\mathrm{Na}$ Argentina, em 2009, foi promulgada uma lei que reconhecia o direito de o paciente dispor sobre suas vontades por meio de diretivas antecipadas; todavia, a lei não mencionava detalhes sobre o tema. Dessa maneira, em 2012, essa legislação foi alterada, abordando a temática de maneira direcionada. A legislação na Argentina determina que as diretivas antecipadas podem ser realizadas por qualquer pessoa adulta capaz, podendo consentir ou recusar determinados tratamentos médicos, preventivos ou paliativos, bem como as decisões que envolvem sua saúde. As diretivas devem ser aceitas pelo médico assistente, exceto as que envolvem o desenvolvimento de práticas de eutanásia, que serão consideradas como não existentes. A declaração será feita, por escrito, podendo ser revogada a qualquer momento. ${ }^{20}$

No Brasil, a resolução das diretivas prevê que o médico registre, no prontuário, as DAV que lhe forem diretamente comunicadas pelo paciente. Não sendo conhecidas as orientações prévias, nem havendo representante designado, familiares disponíveis ou consenso entre esses, o médico recorrerá ao Comitê de Bioética da instituição, caso exista, ou, na sua falta, à Comissão de Ética Médica do hospital ou ao Conselho Regional e Federal de Medicina para fundamentar sua decisão sobre conflitos éticos, quando entender essa medida necessária e conveniente. ${ }^{3}$

Em Portugal, a discussão começou em 2006, com a apresentação do projeto de lei de autoria da Associação Portuguesa de Bioética. Entretanto, apenas em julho de 2012 foi promulgada a lei que regulamenta as DAV, designadamente sob a forma de TV, com a nomeação de procurador de cuidados de saúde. Ainda, foi criado o Registro Nacional do Testamento Vital (RENTEV) que tem por finalidade registrar, organizar e manter atualizada, quanto aos cidadãos nacionais, estrangeiros e apátridas residentes em Portugal, a informação e documentação relativas ao documento de DAV e à procuração de

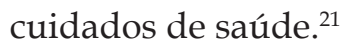

Em Portugal, as diretivas antecipadas são eficazes por cinco anos e representam um documento unilateral e livremente revogável e modificável a qualquer momento, no qual uma pessoa maior de idade e capaz, que não se encontre interditada ou inabilitada por anomalia psíquica, manifesta antecipadamente a sua vontade consciente, livre e esclarecida, no que concerne aos cuidados de saúde que deseja receber, ou não deseja receber, no caso de, por qualquer razão, encontrar-se incapaz de expressar a sua vontade pessoal e autonomamente. ${ }^{21}$ Já no Brasil, não consta a delimitação de tempo, entendendo-se que uma vez realizada, se não for suspensa pelo indivíduo, ela valerá por tempo indeterminado. ${ }^{3}$

No Uruguai, a legislação prevê o direito de expressar as suas vontades no sentido de se opor à futura aplicação de tratamentos e procedimentos médicos para prolongar a vida em detrimento da sua qualidade, caso se encontre em situação de doença terminal, incurável e irreversível. O diagnóstico de estado terminal de uma doença incurável e irreversível deverá ser certificado pelo médico assistente e confirmado por um segundo médico no histórico médico do paciente. ${ }^{19}$ Além disso, a diretriz antecipada pode ser revogada oralmente ou por escrito, a qualquer momento, e, em todos os casos, o médico deverá registrar essa manifestação no prontuário médico. $\mathrm{O}$ documento deve sempre incluir a nomeação de uma pessoa como representante, maior de idade, para assegurar o cumprimento dessa vontade, no caso em que o titular se torne incapaz de tomar decisões por si mesmo. ${ }^{19}$

Caso o paciente em fase terminal de uma doença incurável e irreversível não tenha expressado sua vontade e se encontre incapaz de expressá-la, a suspensão dos tratamentos ou procedimentos será uma decisão do cônjuge ou companheiro de direito comum ou, na sua falta, de familiar em seu primeiro grau de consanguinidade. ${ }^{19}$ Assim, os serviços de saúde públicos e privados devem garantir o cumprimento da diretriz antecipada do paciente, incorporando-a em seu histórico médico, fornecer programas educacionais para funcionários e usuários sobre os direitos dos pacientes prescritos 
na presente lei, cabendo ao Ministério da Saúde implementar uma ampla distribuição do processo educacional. ${ }^{19}$

Na Inglaterra, a Lei da Capacidade Mental inclui, em um dos seus capítulos, as decisões relativas às diretivas antecipadas que devem ser realizadas por uma pessoa com capacidade de consentir com a realização ou continuação do tratamento, podendo retirar ou alterar a decisão a qualquer momento, enquanto capaz de fazê-lo. ${ }^{17}$

No México, a lei das diretivas antecipadas é de ordem pública e de interesse social. Possibilita a recusa de submeter-se a meios, tratamentos e/ ou procedimentos médicos que pretendam prolongar desnecessariamente a vida, protegendo a dignidade humana quando for impossível manter a vida naturalmente. A aplicação das disposições da presente lei é relativa à ortotanásia, não permitindo abreviar a vida intencionalmente. ${ }^{18}$

Nessa perspectiva, no Brasil, as diretivas antecipadas, na prática, significam a realização da ortotanásia que é reconhecida como lícita pelo $\mathrm{CFM}^{22}$ e pela sentença do processo judicial de número 2007.34.00.014.809-3, ou seja, permite que o paciente morra naturalmente, pois não existem mais artifícios oriundos da medicina que possam reverter o quadro; em síntese, nada pode ser feito com o intuito de curá-lo. ${ }^{23}$

É conveniente destacar que as legislações pesquisadas apresentam nas suas estruturas menções sobre: o direito à objeção de consciência pelos profissionais da saúde e a isenção de discriminação no acesso a cuidados de saúde em virtude de ter ou não um documento de DAV. Ainda, todas as legislações mencionam a possibilidade de nomear um representante para agir diante das decisões quando os indivíduos tornam-se incapazes.

Direcionando o olhar para o previsto no Brasil, nota-se que a Resolução do $\mathrm{CFM}^{3}$ também menciona que o médico, caso a declaração prévia de vontade do paciente terminal vá de encontro aos ditames de sua consciência, poderá recusar-se a implementá-la, desde que haja outro médico de prontidão, apto e disposto a assumir seu lugar. Contudo, de maneira alguma, o médico poderá agir de acordo, unicamente, com sua consciência, prevalecendo a vontade manifestada pelo paciente sobre a do médico.

\section{Direito ao respeito da autonomia do paciente}

$\mathrm{O}$ direito do paciente em decidir sobre as pretensões futuras dos tratamentos a que deseja ou não ser submetido em situações de incapacidades é assegurado em todas as legislações pesquisadas. As diretivas antecipadas tornaram-se lei federal em 1991, nos EUA, com a publicação do Patient SelfDetermination Act (PSDA) e preveem o direito do paciente de participar das decisões que envolvem os cuidados relacionados à sua saúde e determinam que os prestadores de serviços mantenham políticas e procedimentos para prestar informações por escrito a cada um dos indivíduos sobre: seus direitos de decidir sobre a assistência médica, incluindo o direito de aceitar ou recusar tratamento médico ou cirúrgico e de formular diretivas antecipadas. ${ }^{14}$ Desse modo, as DAV situam-se no âmbito da autonomia do paciente, além de ser considerado como uma das principais motivações dos pacientes para completá-las o fato de assegurar sua autonomia e afirmá-la, sobretudo, à eventual obstinação terapêutica. ${ }^{24}$

A palavra autonomia significa o "autogoverno, direitos de liberdade, privacidade, escolha individual, liberdade da vontade, ser o motor do próprio comportamento e pertencer a si mesmo" .25:137 Respeitar o paciente autônomo é, no mínimo, reconhecer seu direito de ter suas opiniões, fazer suas escolhas e agir com base em seus valores e crenças pessoais. Neste sentido, o avanço da autonomia humana, nas últimas décadas, conferiu ao paciente o direito a ser informado, fazer a escolha do tratamento, dentre os disponíveis, e consentir ou recusar um procedimento ou terapêutica proposta. ${ }^{5}$ Assim, o respeito à autonomia do paciente leva em consideração a maneira própria de o paciente apreender o mundo, de fazer suas escolhas fundamentadas em valores próprios, agindo de acordo com seus princípios, suas crenças e sua visão do mundo. Desse modo, os profissionais da saúde devem caminhar lado a lado com o paciente, ajudando-o em suas decisões, nunca julgando ou decidindo por ele. ${ }^{26}$

No Brasil, a vontade do paciente é soberana, pois o $\mathrm{CFM}^{11}$ estabelece que é vedado ao profissional deixar de garantir ao paciente o exercício do seu direito de decidir livremente sobre sua pessoa ou seu bem-estar, bem como de exercer sua autoridade para limitá-lo, além do direito do paciente ou de seu representante legal de decidir sobre a execução de práticas diagnósticas ou terapêuticas, salvo em caso de iminente risco de morte. Dessa maneira, de acordo com a Resolução 1.995/12, o médico responsável pelo tratamento, ciente da vontade declarada do paciente, deverá registrá-la no prontuário, para que se possa valer da vontade manifestada previamente. ${ }^{3}$ Com efeito, os profissionais médicos deverão cumprir as normativas das resoluções, conforme estabelece o CFM, determinando que é 
vedado desobedecer aos acórdãos e às resoluções dos Conselhos Federal e Regionais de Medicina ou desrespeitá-los, ficando assim sujeitos às penalidades previstas em lei. ${ }^{11}$

Na Bélgica, o paciente não tem apenas direito, mas também a responsabilidade de cooperar com o profissional de saúde, de que a partir dessa relação entre o paciente e os profissionais da saúde seja propiciada a melhora da qualidade de saúde, resumindo os direitos básicos e as ressalvas para manter os registros de saúde e o acesso a esses registros. É também possível determinar a(s) pessoa(s) que pode $(\mathrm{m})$ representar os pacientes incapazes de exercer seus próprios direitos. Os serviços são prestados respeitando a dignidade da pessoa humana e a autonomia do paciente, além de o paciente ter o direito de dar seu consentimento informado, prévio e voluntário para qualquer intervenção do profissional de saúde. Se o paciente não quiser receber a informação, o profissional de saúde deve respeitar o seu desejo, notificando nos registros de saúde. ${ }^{16}$

$\mathrm{Na}$ Espanha, a dignidade da pessoa humana, o respeito pela autonomia da sua vontade e sua privacidade servem como orientação de todas as atividades. O paciente decide livremente, depois de receber a informação adequada, em uma linguagem compreensível e acessível às suas necessidades, e de obter ajuda para tomar decisões de acordo com sua própria vontade, entre as opções clínicas disponíveis. Qualquer profissional envolvido na atividade de cuidado necessita não só realizar a prestação adequada de procedimentos, mas também executar os deveres de informação e de documentação clínica, além de respeitar as decisões livres e voluntárias do paciente..$^{15}$ Entretanto, há também o direito ao respeito de não serem informados. Ou seja, o direito à informação sobre a saúde dos pacientes pode ser limitado pela existência de um estado de necessidade terapêutica, ou seja, quando o conhecimento da sua situação possa prejudicar a sua saúde. Nesse caso, o médico irá gravar as circunstâncias e comunicará a sua decisão às pessoas relacionadas com o paciente, familiares ou de fato. ${ }^{15}$ No Uruguai, qualquer pessoa maior de idade e mentalmente capaz, numa base voluntária, consciente e livre, tem o direito de se opor à aplicação de tratamentos e procedimentos médicos, a menos que isso afete a sua saúde ou possa afetar a saúde de outros. ${ }^{19}$

Na Argentina, deve ser assegurado que o paciente, na medida de suas possibilidades, participe na tomada de decisões ao longo do seu processo de saúde, e a legislação enfatiza o direito à liberdade de escolha, ou seja, o paciente tem o direito de aceitar ou de rejeitar determinadas terapias ou processos médicos ou biológicos, com ou sem justa causa, bem como revogar posteriormente a sua manifestação de vontade. A atuação profissional deve respeitar a decisão do paciente e deve proceder os registros. ${ }^{20}$ $O$ paciente terminal seguramente informado tem $o$ direito de expressar sua vontade quanto à rejeição de procedimentos cirúrgicos, reanimação artificial ou retirada de suporte de vida, quando são extraordinários ou desproporcionais em relação à perspectiva de melhoria ou quando produzem sofrimento excessivo. Pode também recusar procedimentos alimentares e hidratação quando ocorrem como o único efeito do prolongamento do tempo da fase final..$^{20}$

No que se refere às restrições de hidratação e alimentação artificiais, muitos caracterizam essa decisão como eutanásia, prática proibida pelo ordenamento jurídico brasileiro. ${ }^{1}$ Nesse sentido, a suspensão tem um significado predominantemente simbólico, ou seja, familiares e profissionais, muitas vezes, diante da suspensão desses recursos vitais sofrem por achar que e o paciente morreu de fome e sede, embora estudos comprovem que, em determinados quadros clínicos, o paciente não absorve de forma satisfatória a hidratação e a nutrição. ${ }^{27}$

Embora não se disponha legislação brasileira explícita sobre TV, existem além do amparo da Resolução 1.995/12, ${ }^{3}$ menções na Constituição Brasileira ${ }^{9}$ sobre os princípios constitucionais da Dignidade da Pessoa Humana (art. 1, III), da Autonomia Privada (princípio implícito no art. 5o) e a proibição constitucional de tratamento desumano (art. $5^{\circ}$, III), que implicam na afirmação de que se reconhece a manutenção da dignidade humana, da autonomia do ser humano, além do direito a não ser submetido a um tratamento que não deseja que seja realizado. Assim, as decisões profissionais médicas, respeitando seus ditames de consciência e as previsões legais, aceitarão as escolhas de seus pacientes, relativas aos procedimentos diagnósticos e terapêuticos por eles expressos, desde que adequadas ao caso e cientificamente reconhecidas. ${ }^{11}$

Partindo do exposto, confirma-se a necessidade de respeitar a autonomia do paciente, quando na Resolução 1.995/12 está exposto que as DAV do paciente prevalecerão sobre qualquer outro parecer não médico, inclusive sobre os desejos dos familiares. Entretanto, o médico deixará de considerar as DAV do paciente ou de seu representante que, em sua análise, estiverem em desacordo com os preceitos ditados pelo CFM. ${ }^{3}$ Além disso, é vedado ao médico deixar de obter consentimento do paciente ou de seu representante legal após esclarecê-lo sobre 
o procedimento a ser realizado, exceto em caso de risco iminente de morte.

Entretanto, corroborando com o previsto na legislação da Espanha, o CFM, no Brasil, prevê que não é permitido deixar de informar ao paciente o diagnóstico, o prognóstico, os riscos e os objetivos do tratamento, salvo quando a comunicação direta possa lhe provocar dano, devendo, nesse caso, ser realizada a comunicação a seu representante legal. ${ }^{11}$

Com base na ideia de que as diretivas antecipadas no Brasil possibilitam ao indivíduo dispor sobre sua aceitação ou recusa de tratamentos extraordinários, em caso de terminalidade da vida, o direito fundamental à liberdade previsto na Constituição Federal confirma o direito de autonomia do paciente. ${ }^{9}$ Dessa maneira, a declaração prévia de vontade do paciente terminal corresponderia à possibilidade do exercício do direito fundamental à liberdade de forma genuína, uma vez que esse documento nada mais é do que um espaço que o indivíduo tem para tomar decisões pessoais que são, e devem continuar a ser, imunes a interferências externas, sejam elas dos médicos, das famílias ou de qualquer pessoa e/ou instituição que pretenda impor sua própria vontade. ${ }^{1}$

Complementa-se, ainda, que, além da Constituição Federal, o Código Civil prescreve que ninguém pode ser constrangido a submeter-se, com risco de vida, a tratamento médico ou intervenção cirúrgica. ${ }^{10}$ Assim, a DAV do paciente terminal é instrumento garantidor desse dispositivo legal, uma vez que evita o constrangimento de o paciente ser submetido a tratamentos médicos fúteis que apenas potencializam o risco de vida, já que os procedimentos médico-hospitalares sempre representam risco.

\section{CONCLUSÃO}

A aceitação da morte não é uma tarefa fácil; falar sobre a própria morte estando saudável é diferente da situação de receber o diagnóstico de que possui apenas alguns meses de vida. Nesse sentido, se a morte é inevitável, tratá-la como um processo irreversível auxiliaria a inclusão do morrer bem, já que muitas vezes a morte acontece em situações desumanas. Os novos recursos tecnológicos permitem a adoção de medidas desproporcionais que podem prolongar o sofrimento do doente terminal, sem lhe trazer benefícios, e essas medidas podem ter sido antecipadamente por ele rejeitadas. Assim, os casos de recusa ou de rejeição dos procedimentos significam a interrupção de medidas e ações para o adequado controle e alívio do sofrimento do paciente.
Conhecer as legislações vigentes em diferentes países corrobora com a discussão de que é imprescindível aderir a essa ferramenta, no sentido de evitar que pessoas que podem atualmente nem pensar sobre o assunto, futuramente poderão vir a sofrer desnecessariamente por não terem deixado decididas as vontades. Contribui, ainda, para subsidiar discussões, no Brasil, para que não somente os médicos, que detêm a prerrogativa do diagnóstico, mas, também os profissionais da saúde que atuam direta e intensivamente com os pacientes considerados terminais possam atuar considerando os desejos dos pacientes assistidos.

As recomendações propostas na Resolução sobre as diretivas, no Brasil, parecem generalizáveis sem se deter em detalhes operacionais de conduta, como ocorre nas legislações dos outros países. Falase sobre a necessidade da legalização da prática, a fim de desvincular de ações que poderão se tornar ilegais, em virtude do deficiente amparo que a Resolução brasileira prevê. Indubitavelmente, é um grande avanço e, além da resolução atual, é possível considerar que já existem outras determinações, como a constitucional, a civil, entre outras; no entanto, é preciso deter-se na sua operacionalização, a fim de proteger os profissionais, os familiares e, principalmente, o paciente para que tenha sua vontade atendida quando não for mais capaz de participar ativamente das decisões que envolvem sua vida.

\section{REFERÊNCIAS}

1. Dadalto L. Distorções acerca do testamento vital no Brasil (ou o porquê é necessário falar sobre uma declaração prévia de vontade do paciente terminal). Revi Bioética y Derecho. 2013; 28: 61-71.

2. Bomtempo VT. Diretivas antecipadas: instrumento que assegura a vontade de morrer dignamente. Rev Bioética y Derecho. 2012 set; 26:22-30.

3. Conselho Federal de Medicina. Resolução n. 1.995, de 9 de agosto de 2012. Dispõe sobre as diretivas antecipadas de vontade dos pacientes. [cited 2013 Set 05]. Available from: http://www.portalmedico.org. br/resolucoes/CFM/2012/1995_2012.pdf

4. Piccini, CF, Steffani JA, Bonamigo EL, Bortoluzzi MC, Schlemper Jr BR. Testamento Vital na perspectiva de médicos, advogados e estudantes. Rev Bioethikos. 2011; 5(4):384-91.

5. Campos, MO, Bonamigo EL, Steffani JA, Piccini CF, Caron R. Testamento vital: percepção de pacientes oncológicos e acompanhantes. Rev Bioethikos. 2012; 6(3):253-259.

6. Loureiro JC. Saúde no fim de Vida: entre o amor, o Saber e o Direito. Revista Portuguesa de Bioética. 2008; 4: 38-83. 
7. Cellard A. A análise documental. In: Poupar TJ. et al. A pesquisa qualitativa: enfoques epistemológicos e metodológicos. Petrópolis (RJ): Vozes; 2008. p. 295316.

8. Testamento Vital [Internet]. Legislação; 2013. [cited 2013 Set 02]. Available from: www.testamentovital. com.br

9. Brasil. Constituição da República Federativa do Brasil, de 05 de outubro de 1988. Diário Oficial da República Federativa do Brasil, 05 out 1988.

10. Brasil. Lei n. 10.406, de 10 de janeiro de 2002. Institui o Código Civil. Diário Oficial da República Federativa do Brasil, 12 de jan 2002.

11. Conselho Federal de Medicina. Resolução n. 1.931/2009. [cited 2013 Out 07] Available from: www. cremego.cfm.org.br.

12. Urionabarrenetxea KM. Reflexiones sobre el testamento vital (I). Aten Primaria. 2003; 319 (1):52-54.

13. Bardin L. Análise de conteúdo. Lisboa: Edições 70; 2011.

14. Estados Unidos da América. Patient self determination act of 1990 de 18 jul de 1990. [cited 2013 Set 06]. Available from: http://thomas.loc.gov/cgi-bin/ query/z?c101:H.R.5067.IHInglaterra. Mental Capazity Act 2005

15. Espanha. Ley n. 41/2002, de 14 de noviembre. Básica reguladora de la autonomía del paciente y de derechos y obligaciones en materia de información y documentación clínica. Boletín Oficial del Estado. [cited 2013 Nov 05]. Available from: http:/ / www.boe. es/buscar/doc.php?id=BOE-A-2002-22188

16. Bélgica. The Law of 22 August 2002 on the Rights of Patients. Belgian Official Gazette,26 Set 2002. [cited 2013 Nov 07]. Available from: www.patientrights.be

17. Inglaterra. Mental Capazity Act 2005. [cited 2013 Nov 07]. Available from: http:/ / www.legislation.gov.uk/ ukpga/2005/9/contents.

18. México. Decreto por el que se expide la ley de voluntad anticipada para el distrito Federal. Gaceta oficial del distrito federal,7 de Enero de 2008. [cited 2013 Nov 07]. Available from: http://mexico.justia. com/estados/df/leyes/ley-de-voluntad-anticipadapara-el-distrito-federal/
19. Uruguai. Ley n. 18.473. Voluntad Anticipada. Diario oficial, 21 Abr 2009. n. 2771. [cited 2013 Nov 07]. Available from: http://www.parlamento.gub.uy/ leyes $/$ AccesoTextoLey.asp?Ley=18473\&Anchor=

20. Argentina. Ley n. 26.742, de 09 de mayo de 2012. Modifícase da Ley n. 26.529 que estableció los derechos del paciente em relación con los profesionales e instituciones de la salud. [cited 2013 Nov 06]. Available from: http:/ / www.infoleg.gov.ar/infolegInternet/ anexos/195000-199999/197859/norma.htm

21. Portugal. Lei n. 25/2012, de 16 de junho. Regula as diretivas antecipadas de vontade, designadamente sob a forma de testamento vital, e a nomeação de procurador de cuidados de saúde e cria o Registro Nacional do Testamento Vital. Diário da República. 16 jul 2012; (136): 3728,1a série. [cited 2013 Nov 06]. Available from: http://dre.pt/ pdf1sdip/2012/07/13600/0372803730.pdf

22. Conselho Federal de Medicina. Resolução $n^{\circ} 1.805$, de 9 de novembro de 2006. [cited 2013 Nov 05]. Available from: www.portalmedico.org.br.

23. Justiça Federal do Distrito Federal. Processo n. 2.007.34.00.014809-3. [cited 2013 Set 05]. Available from: www.jfdf. jus.br/destaques/14\%20VARA_01\%20 12\%202010.pdf

24. Pautex S, Herrmann FR, Zulian GB. Role of advance directives in palliative care units: a prospective study. Palliative medicine. 2008; 22(7): 835-41.

25. Beuchamp TL, Childress JF. Princípios de ética biomédica. São Paulo (SP): Loyola; 2002.

26. Vargas MAO, Vivan J, Vieira RW, Mancia JR, Ramos FRS, Ferrazzo $S$ et al. Ressignificando o cuidado em uma unidade especializada em cuidados paliativos: uma realidade possível?. Texto Contexto Enferm [Internet]. 2013 Set [cited 2014 Jun 27]; 22(3):637-45. Available from: http://www. scielo.br/scielo.php?script=sci_arttext\&pid=S010407072013000300009\&lng=pt

27. Pessini L. A filosofia dos cuidados paliativos: uma resposta diante da obstinação terapêutica. In: Bertachini L, Pessini L. Humanização e cuidados paliativos. $3^{a}$ ed. São Paulo (SP): Loyola; 2004. p. 181-208. 